Affective symptoms in adult siblings of people with developmental disabilities

\title{
Anxiety and Depression Symptomatology in Adult Siblings of Individuals with Different Developmental Disability Diagnoses
}

\begin{abstract}
Factors predicting the emotional well-being of adult siblings of those with developmental disability (DD) remain under-researched. In this study adult siblings of individuals with Down's syndrome, autism, Prader-Willi syndrome and those with DD but with unknown aetiology were compared with each other and a closely-matched control group to ascertain if sibling disability type made a difference to anxiety and/or depression levels. Also considered was the interactive effect of gender, age, parental and sibling educational attainment levels, socio-economic status and birth order on anxiety and depression outcomes. With the exception of siblings of those with Down's syndrome, adult siblings of those with ASD, PWS and DUA reported significantly higher levels of anxiety and depression than the control group. There were some predictive effects for anxiety and depression of the demographic variables but none common to all disability types and no moderating effects of demographic factors were found. Consequently other solutions must be found as to why this important group of people have elevated rates of anxiety and depression in comparison to the general population.
\end{abstract}

\section{Highlights}

- All DD sibling groups were in the borderline clinical anxiety range

- All groups were well below borderline category for depression symptoms

- Siblings of those with ASD or PWS had significantly higher anxiety levels than control

- Younger siblings of those with DS and PWS had higher affective levels than older ones 
Affective symptoms in adult siblings of people with developmental disabilities

- Demographics do not appear responsible for sibling anxiety or depression outcomes

\section{Keywords}

Adult siblings; developmental disabilities; anxiety; depression; demographics; birth order

\section{Introduction}

Sibling relationships can offer one of the most mutually supportive and enduring bonds over the course of a lifetime (Bank \& Kahn, 1997; Voorpostel \& Blieszner, 2008), improving emotional, cognitive and social growth (Brody, 2004). It is a relationship that exists through circumstance and because of shared influences it is often a relationship of relative equals (Cicirelli, 1995). However, when one of the siblings has a developmental disability (DD) the relationship can be viewed as a caring function as opposed to being reciprocally supportive (McHale \& Gamble, 1989; Turnbull \& Turnbull, 1990); this may result in affective (anxiety AND depression) consequences for the sibling without disabilities, particularly as many with DD retain a lifelong reliance upon their families (Wolfe, Song, Greenberg \& Mailick, 2014). The characteristics of the type of DD can also affect sibling outcome, with, for example, siblings of individuals with Down's syndrome (DS) usually having better overall health, including fewer reported depression symptoms than those who have siblings with autistic spectrum disorder (ASD) (e.g., Hodapp \& Urbano, 2007). Research to date has usually focused on sibling affective outcomes in childhood, consequently there is relatively little information available on adult sibling affective outcome, in particular, if it is the characteristics of the disability or if it is the interactive effect of demographic factors that account for the outcomes.

\subsection{Influences of disability types on sibling affective outcome}


Affective symptoms in adult siblings of people with developmental disabilities

Adult siblings of individuals with DS, in comparison to ASD, have better sibling relationships, health, affective health and more contact with their sibling with intellectual disabilities (Hodapp \& Urbano, 2007). This is a trajectory that appears to be continued from childhood because, as children, siblings of individuals with DS can emerge as better adjusted than normative control samples (Hastings, 2007). Conversely, $40 \%$ of children who have siblings with ASD report scores on affective disorders that place them on the at-risk or clinical range, compared to between $6-13 \%$ in typically developing samples (Ross \& Cuskelly, 2006). Smith and Perry (2005) found that $36 \%$ of children and adolescents who have a sibling with ASD report borderline or clinically significant internalising problems. Siblings of children with ASD and an intellectual disability have more emotional problems than children who have siblings with only an intellectual disability or a control sample (Petalas, Hastings, Nash, Lloyd \& Dewey, 2009). Possible reasons for this increased vulnerability include the increasing age of the child with autism, being younger than the child with autism and the possibility of phenotypic similarities. However, when Orsmond, Kuo and Seltzer (2009) specifically compared adolescents and adults who have a sibling with ASD there was no difference in depressive symptoms found between adolescence and adulthood; noticeably, neither age group reported symptoms near to the cut-off point for clinical depression. The differences in these findings may be due to comparing children with adolescents and adults and possibly some ameliorative affective mechanism occurs as the sibling ages.

Similar to individuals with ASD, those diagnosed with Prader-Willi syndrome (PWS) are characterised by maladaptive behavioural tendencies (Dimitropoulos \& Schultz, 2007; Veltman et al., 2004), often associated with mild mental retardation (Cassidy \& Driscoll, 2009). PWS is caused by a sporadic chromosomal disorder and tends to be diagnosed in infancy (Cassidy \& Driscoll, 2009). However, despite many disabilities such as DS, ASD and 
Affective symptoms in adult siblings of people with developmental disabilities

PWS, having a clear diagnosis, in approximately $40 \%$ of individuals who have moderate to severe intellectual disability there is no known diagnosis (Knight et al., 1999). This can be particularly stressful because without a diagnosis, there can be no realistic prognosis. It also limits participation in specific support groups, which can be isolating for the family.

\subsection{Demographic influences on sibling affective outcome}

There is a greater general propensity for females to report higher affective symptoms than males (e.g., McLean, Asnaani, Litz \& Hofmann, 2011); however, research has been inconsistent in reporting gender outcomes for siblings. Hannah and Midlarsky (1999) reported that sisters of children with disabilities scored higher on affective disorders than brothers, possibly because they play a larger part in their sibling's caretaking; however, a meta-analysis found no gender differences in affective disorders (Rossiter \& Sharpe, 2001). Conversely, Hastings (2003) reported that brothers of children with ASD had more adjustment difficulties than sisters.

Higher parental educational attainment and levels of household income can help family adjustment and ameliorate stress, due to a greater ability to access and pay for support (Bramlett \& Mosher, 2002; Hastings, 2003). However, decrements in math and language achievements were witnessed as early educational experiences for siblings, alongside an increased likelihood to have to repeat a grade (Fletcher, Hair \& Wolfe, 2012). Conversely, Wolfe et al (2014) found normative levels of education and employment in adult siblings. Lower levels of socio-economic status (SES) tend to be associated with increased adjustment problems in children whose siblings have disabilities but that this risk can be ameliorated by lower levels of parental stress (Giallo \& Gavidia-Payne, 2006; Macks \& Reeve, 2007). Hartley, Barker, Baker, Seltzer and Greenberg (2012) found in families who have a child with ASD that household income significantly affected maternal marital satisfaction, which 
Affective symptoms in adult siblings of people with developmental disabilities

general studies show can impact upon the whole family (e.g., Gudmunson, Beutler, Israelsen, McCoy \& Hill, 2007).

\subsection{Familial influence on sibling affective outcome}

In addition, being older than the sibling with disabilities is associated with better adjustment scores (Hastings, 2003). Younger siblings often worry about overtaking their older sibling with disabilities either academically or physically (Turnbull \& Turnbull, 1990), they may suffer from more emotional problems (Petalas et al., 2009), and, due to extra caregiving responsibilities may be more likely to have elevated rates of affective disorders (Gold 1993). Conversely, Macks and Reeve (2007) report siblings emotional adjustment patterns were more at risk when older than their sibling with ASD.

\subsection{The present study}

Research into the affective condition of adult siblings of individuals with disabilities is relatively limited and conflicting. It is known that adult homo or heterotypic patterns of affective issues is best predicted by previous disorders, often from childhood or adolescence (Copeland et al., 2013). The majority of studies that have taken place to date have mainly focused on childhood adjustment (e.g., Cuskelly \& Gunn, 2006; Petalas et al., 2009); however, with the progression of medical technology, it is now common for individuals with disabilities to have much longer lifespans (Seltzer, Greemberg, Orsmond \& Lounds, 2005). Consequently, there is a requirement to examine the long-term outcomes for these siblings because in many instances adult siblings will assume responsibility for their sibling with disabilities once the parents are no longer able to do so (Davys, Mitchell \& Haigh, 2015b). It is of paramount importance that the siblings are psychologically healthy in order for them to be able to cope with the undertaking of responsibility for their sibling with disabilities, while potentially looking after children of their own, maintaining careers and sometimes caring for 
Affective symptoms in adult siblings of people with developmental disabilities

elderly parents (Davys, Mitchell \& Haigh, 2015a). Our study therefore aims to question whether elevated rates of anxiety and /or depression actually do exist in adult siblings in comparison to the general population, or whether affective levels stabilise once the individual is no longer as influenced by the day-to-day challenges of living with their sibling with disabilities. Having a sibling with disabilities is not in itself sufficient cause to experience higher affective levels; consequently, we also examine potential risk factors as informed by previous research. Therefore, based upon reviewing the above research, the hypotheses for our study are:

1. There will be a difference in the levels of anxiety and depression symptomatology reported by the sibling group and the control group; however, the levels reported may vary depending upon sibling disability type.

2. Gender will be associated with affective symptomatology.

3. Participant educational attainment, parental education and income levels will be predictive of lower levels of affective symptomatology.

4. Being born before or after the sibling with disabilities will have an influence on adult sibling symptomatology for each of the DD sibling groups.

5. There will be individual moderating effects of gender, age, SES, participant educational level, maternal and paternal educational levels influencing the relationship between having a sibling with disabilities and anxiety and depression.

\section{Methods}

\subsection{Participants}

\subsubsection{Participants who have a sibling with a disability}


Affective symptoms in adult siblings of people with developmental disabilities

The participants were selected on the basis of being non-disabled siblings of individuals with disabilities and were over 18 years old. The participants were advertised for through UK disability charities, including Sibs, the Down's Syndrome Association, the National Autistic Society and the Prader-Willi Society. For reasons of confidentiality we were not permitted direct access to the databases but the charities agreed to post questionnaires directly to potential participants or advertise for participants via their newsletters or websites. The voluntary sample under study included 132 adults who have a sibling with DS $(n=59)$, ASD $(n=31)$, PWS $(n=26)$ or those who have a sibling with DUA $(n=16)$. The age range varied from 19 - 71. The sex split was $34(25.8 \%)$ male and $98(74.2 \%)$ female. The majority of 82 participants were married or cohabiting (62.1\%), with $45(34.1 \%)$ single and $5(3.8 \%)$ divorced or separated. The employment level of employment was working in intermediate occupations, with an average salary of under $£ 30,000$. An undergraduate university degree was the mean level of education acquired. The participants were split into groups depending upon their sibling's disability type. The characteristics for each group are shown in Table 1.

\subsubsection{Control group participants}

A further 193 participants responded to a questionnaire, which was distributed through the University, friends, families, colleagues and local businesses; 132 were included on the basis of their matching power to the sibling group and having at least one sibling but no sibling with disabilities. Previous research has highlighted the importance in disability research of matching on a case-by-case basis in order to ensure that demographic differences do not skew group data (Stoneman, 1989). Consequently, the control group was matched to the sibling group on a one-to-one basis; gender was always applied. Age was applied to within ten years, with the mean age for the sibling group being $33.83( \pm 10.69)$ and the control group $37.03( \pm$ 12.34). Marital status was applied in the majority of cases. Furthermore, socio-economic 
Affective symptoms in adult siblings of people with developmental disabilities

status was usually applied to within 1 point on employment status and annual income. The full range of data for the control group can be seen in Table 1.

\subsection{Measures}

\subsubsection{Demographic information}

Employment status was rated from 0 for not working to 7 for working in a highly qualified professional area, according to the UK National Statistics Socio-economic Classification (Hall, 2006). Annual income was scored from 1-7, respectively, whereby under $£ 10,000$, $£ 10,001-15,000, £ 15,001-20,000, £ 20,001-30,000, £ 30,001-45,000, £ 45,001-70,000$ or $£ 70,001+$. The highest level of educational attainment was requested for the participant and their mother and father, with the choice of none, technical, GCSE or equivalent, 'A' levels, undergraduate degree or postgraduate qualification, scoring from $0-5$, respectively.

\subsubsection{The Hospital Anxiety and Depression Scale (HADS, Zigmond \& Snaith, 1983)}

The HADS was used to assess affective symptoms. It is a 14-point, self-report scale, which assesses both depression and anxious symptomatology, with scores above 7 indicating borderline problems and $11+$ scores indicating clinical levels. HADS is suitable for use in a non-psychiatric setting (Snaith, 2003) and has proven reliability and validity (Bjelland, Dahl, Haug \& Neckelmann, 2002). This study had high reliability for both anxiety and depression (Cronbach's alpha reliabilities were .85 and .74 , respectively). Also pertinent is that anxiety and depression are clearly delineated, making it easier to assess which affective symptoms were evident within the different participant groups.

\subsection{Procedure}

After acquiring approval from the University ethical committee, a paper or electronic questionnaire would then be sent to the participant, depending upon preference. The 
Affective symptoms in adult siblings of people with developmental disabilities

participants would then privately complete the questionnaire and return it to us in the preaddressed envelope or electronically. The postal responses had no identifying markers and thus were guaranteed anonymity. Anonymity was ensured in the electronic versions because upon submission the questionnaire was allocated a random number, then stored in a separate folder and the original email was deleted, thus no identifying markers were present.

\subsection{Statistical analysis}

This was a cross-sectional, between-subjects study design, completed by self-report. All variables were initially calculated for mean values and standard deviations for each of the groups, which were then tested for differences between the groups through the use of oneway analyses of variance (ANOVAs), followed by a single-step, multiple comparison procedure using Tukey's post hoc tests. Thereafter, moderation analyses were carried out, using correlational analyses and multiple regression. This should help to explain whether the demographic variables of gender, age, socio-economic status and participant or parental educational attainment will moderate the causal effect of having a sibling with disabilities on affective symptomatology (Frazier, Tix \& Barron, 2004). Certain criteria for design, measurement and analysis were considered due to the characteristic problem of low statistical power in moderated multiple regression analysis (Aguinis \& Gottfredson, 2010). The potential design issue of sample size was considered; the problem mainly arises when the sample subgroup proportions are unequal (a $50 / 50$ population base is optimum); this was addressed by having exactly the same amount of participants in the sibling and control groups so, therefore, there should be no decrease in power. The continuous variables were standardised (Frazier et al., 2004) and the dichotomous variables were transformed into dummy variables. Unstandardised Beta coefficients, $F$ change values and significance levels were included for each variable, with $R^{2}$ change values and significance values being presented for each step. The alpha level was set at $\mathrm{p}<0.05$. 
Affective symptoms in adult siblings of people with developmental disabilities

\section{Results}

\subsection{Demographic variables for each of the groups}

Table 1 presents demographic information on the groups. There was a predominance of female respondents within each group. Those who have siblings with DUA were older than the other groups, specifically, Tukey's post hoc analysis showed they were significantly older than the group whose siblings have DS (mean difference $=9.28, \mathrm{SE}=3.23, p=0.04$ ), than those whose siblings have ASD (mean difference $=10.31, \mathrm{SE}=3.53, p=0.03$ ) and those whose siblings have PWS (mean difference $=11.85, \mathrm{SE}=3.65, p=0.01$ ). There were no significant differences between marital status, employment status or annual income between the groups. However, those whose siblings have DS had significantly higher educational qualifications than the control group (mean difference $=0.91, \mathrm{SE}=0.19, p<0.001$ ). Further, those who have siblings with DS have mothers with significantly higher educational qualifications than the group whose siblings have DUA (mean difference $=1.98, \mathrm{SE}=0.44, p$ $<0.001)$ and also the control group (mean difference $=1.03, \mathrm{SE}=0.30, p<0.001$ ); similarly, those whose siblings have DS have fathers with significantly higher educational qualifications than the group whose siblings have PWS (mean difference $=1.12, \mathrm{SE}=0.38, p$ $=0.03$ ), whose siblings have DUA (mean difference $=1.83, \mathrm{SE}=0.49, p=0.002$ ) and the control group $($ mean difference $=1.34, \mathrm{SE}=0.27, p<0.001)$.

\section{(Table 1 here)}

Table 1 also shows characteristics that relate solely to the sibling groups. The only significant difference between the groups is that siblings with DUA were significantly older than the siblings with DS (mean difference $=8.36, \mathrm{SE}=2.80, p=0.02$ ), than those whose have ASD (mean difference $=11.27, \mathrm{SE}=3.07, p=0.02$ ) and those who have PWS (mean difference $=12.01, \mathrm{SE}=3.15, p=0.01)$. 
Affective symptoms in adult siblings of people with developmental disabilities

\subsection{Differences in anxiety and depression symptomatology between the groups}

To assess whether there are any affective differences between the sibling groups and the control group a series of one-way ANOVAs and Tukey's post hoc analyses were again carried out (see Table 2). Participants who have siblings with ASD or PWS have significantly higher anxiety levels than the control group (mean difference $=3.18, \mathrm{SE}=0.84, p=0.002$; mean difference $=3.18, \mathrm{SE}=0.89, p=0.04$, respectively). It should be noted that the mean level for all of the sibling groups is in the anxiety borderline category, in contrast to the control group, which is below the borderline range. Tukey's post hoc analysis also showed the group whose siblings have DUA have significantly higher depression levels than the control group (mean difference $=2.56, \mathrm{SE}=0.80, p=0.01$ ) and those whose siblings have ASD showed a non-significant trend to reporting higher depression levels than the control group (mean difference $=1.62, \mathrm{SE}=0.61, p=0.06$ ). However, every group was below the borderline range for depression.

(Table 2 here)

\subsection{Correlations within each sibling group}

We computed bivariate correlations to ascertain if there were any significant associations between the main study variables. The data for those whose siblings have ASD or DUA above the diagonal and siblings of individuals who have DS or PWS below the diagonal (see Tables $3 \mathrm{a}$ and $3 \mathrm{~b}$ respectively). Table $3 \mathrm{a}$ shows the main findings for siblings of those with DS; there are significant positive correlations between anxiety and depression, anxiety and being a sister, high levels of maternal education and being younger than the sibling with DS. Table 3a also shows the only main finding for siblings of those with ASD is the strong association between anxiety and depression. Table $3 \mathrm{~b}$ shows for siblings of those with PWS the main findings are a high association between anxiety and high levels of 
Affective symptoms in adult siblings of people with developmental disabilities

maternal education, also a strong association between depression and being younger than the sibling with PWS. Table $3 \mathrm{~b}$ also shows for siblings of those with DUA there are no associations between the variables chosen and anxiety; however, there are associations between depression symptomatology and increasing age, having a sibling with disabilities whose age is higher and low levels of education.

(Tables $3 a$ and $3 b$ here)

\subsection{Predictors of anxiety and depression within each sibling group}

Ordinary least squares regression models were carried out separately for each of the sibling disability types. For parsimonious reasons the predictors were chosen if they significantly correlated with anxiety or depression for any of the sibling groups. Therefore, due to no significant correlations between the variables tested, no regression analyses were carried out for depression for the siblings of those with DS or ASD or for anxiety for siblings of those with ASD or DUA. Please note that due to sample size constraints, the predictor variables were entered individually in the group those whose siblings have PWS or DUA. The regression model for anxiety symptomatology for siblings of individuals with DS was significant $(F(3,48)=6.94, p=0.001)$; the individual significant predictors for anxiety were being a sister, higher levels of maternal education and being younger than the sibling with DS. The regression model in depression for siblings of individuals who have PWS was not significant $(F(4,21)=2.34, p=0.09)$, however, being younger than the sibling with disabilities did uniquely show significance in predicting depression. The anxiety and depression models for the DUA group showed no significance; however, the individual predictors of age $(F(1,14)=12.17, p=0.004)$, age of the sibling with disabilities $(F(1,14)$ $=7.12, p=0.02)$ and level of education achieved $(F(1,13)=5.47, p=0.04)$ were all significant predictors of depression. 
Affective symptoms in adult siblings of people with developmental disabilities

\subsection{Moderation analyses}

For the moderation analyses, we pooled the sibling groups together in order to increase statistical power. We wanted to ascertain if there were any interactions between the variables under study. We found that the unstandardized regression co-efficient for the whole cohort who have a sibling with disabilities was significant throughout, albeit slightly lower for maternal education levels for anxiety and maternal and paternal education levels for depression. None of the unstandardized regression coefficients for the interaction term were significant, indicating there was no interaction or moderating effect for any of the variables under study upon the relationship between having a sibling with disabilities and anxiety or depression. Further the $R^{2} \Delta$ maximum scores associated with the interaction terms was 0.01indicating that the interaction terms did nothing to increase the explained variance of anxiety or depression in addition to the variance explained by the independent effects of having a sibling with disabilities and the demographic variables (see Tables 4 and 5).

\section{Discussion}

All of the sibling groups reported higher levels of anxiety and depression symptoms than the control group; however, while all the sibling groups were in the borderline category for anxiety, all of the groups were below the borderline range for depression. Those who have siblings with either ASD or PWS scored significantly higher than the control group for anxiety and those who have siblings with ASD or DUA scored significantly higher than the control group for depression. Individuals who have siblings with DS were not significantly different from the control group in the reporting of anxiety or depression.

Interestingly, being a sister of an individual with DS was a significant predictor of anxiety but not for the other sibling groups. Similarly, lower educational levels predicted higher levels of depression but only for those participants whose sibling has DUA. Likewise, 
Affective symptoms in adult siblings of people with developmental disabilities

higher levels of maternal education predicted anxiety only for those individuals who have siblings with DS. However, being younger than the sibling with DS was predictive of anxiety and being younger than a sibling with PWS significantly predicted depressive symptoms. Further, in most sibling groups being the younger sibling showed a trend towards predicting anxiety and /or depression. The interaction between having a sibling with disabilities with gender, age, SES, and participant, mother and father educational attainment levels were all non-significant and did not explain the increased levels of affective disorders. These results indicate that there is no over-riding demographic variable that can explain the increased affective symptomatology in siblings.

A growing body of research indicates that higher levels of educational attainment can act as a protective factor against affective disorders (Bjelland et al., 2008; Gale, Hatch, Batty \& Deary, 2009); this is thought to have a cumulative effect as the individual ages (Bjelland et al., 2008). Gale et al., (2009) gave potential suggestions as to why this might be the case; they proposed that having a higher IQ meant it was less likely that the individual would experience socio-economic disadvantage, which can be indicative of affective disorders. However, despite lower educational attainment being predictive of depressive symptoms in those whose siblings have DUA, they have the second highest levels of SES and annual income when compared to the other groups. These findings might be due to their increased age and therefore longer period of working life or they might be anomalous due to the small sample size; however, they are worthy of further study.

Another interesting atypical finding regards high maternal education levels which are associated with anxiety for the DS and PWS sibling groups; previous research usually suggests that higher maternal educational levels have an ameliorative influence upon affective problems (Hastings, 2003). However, it has been suggested that siblings of individuals with disabilities often implicitly perceive a need from their parents to excel in 
Affective symptoms in adult siblings of people with developmental disabilities

order to compensate for the lack of achievement in the sibling with disabilities (Moore et al., 2002); this was not under study in our current research but speculatively implicit pressure might have caused undue stress within the sibling group, resulting in heightened anxiety levels that have been maintained into adulthood. Interestingly the groups who have siblings with DS and PWS are amongst the highest academic achievers in this cohort and so our finding might be worthy of further exploration.

In line with previous research (Hastings, 2003; Petalas et al., 2009) our findings show that being younger than the sibling with disabilities, especially if the sibling has DS or PWS, is predictive of affective symptomatology. Research has raised concerns from younger siblings regarding overtaking their older disabled siblings either academically or physically (Turnbull \& Turnbull, 1990). Younger siblings might consequently suppress negative feelings regarding their disabled sibling due to guilt (Stoneman, Brody, Crapps \& Malone, 1991). This is an area that we feel deserves further research and gives potential scope for intervention strategies, particularly in light of our previous comments that those who have siblings with DS or PWS are among the highest achievers.

Interestingly, there are some predictive effects of symptomatology where siblings of individuals who have DUA are more likely to report higher levels of depressive symptomatology and, whilst not in the clinical range, it raises a theoretical point about the effects of public awareness and acceptance of disability. The mean age of these participants was approximately ten years older than the other sibling groups and, even in that short generation span, disabilities have become much more widely accepted. It could be that the raising of public awareness and subsequent reduction in discrimination through disability campaigns (e.g., http://www.worlddownsyndromeday.org/ 2013) have had a positive influence, not just on the individual with disabilities but also their siblings and should therefore be encouraged. However, perhaps the higher reporting of depressive symptoms in 
Affective symptoms in adult siblings of people with developmental disabilities

siblings of DUA individuals is due to lack of access to specific disability support groups or intervention schemes because of the absence of diagnosis and is worthy of further exploration.

The exact reasons underlying the increased sibling propensity towards affective issues as shown in this study remain unclear and do not appear to be as a result of the demographic factors we considered. Falk, Norris and Quinn (2014) have reported how socio-economic support is an important contributor to parental mental health; however, in direct contrast, no independent effects of SES were found in the present study, potentially indicating that higher levels of affective problems in the sibling groups are due to cognitive or emotional rather than demographic reasons. This argument follows through as no independent effects were found for age or education attainment levels and the relationship with anxiety; however, being female was independently reported as an indicator of affective disorders. Due to the independence of the effect, however, this result may be due to the general increased propensity of women to report affective symptoms (e.g., McLean et al., 2011) and little to do with the experience of having a sibling with disabilities. Further research is necessary to establish if sisters are more vulnerable to affective disorders as a direct result of sibling disability.

The current results supports previous research indicating that having a sibling with DS does not inevitably cause poor levels of adjustment, with the present group outcome being very similar to the control group (Cuskelly \& Gunn, 2006; Hodapp \& Urbano, 2007). Cuskelly and Gunn (2006) suggested that individuals who have siblings with DS should be addressed on a within-family basis in order to identify specific families at risk. This suggestion should, perhaps, be extended to all families that include a disabled member, particularly if specific risk or resilience factors regarding disability type can be identified. This could have important implications for the future roles of the sibling relationship, 
Affective symptoms in adult siblings of people with developmental disabilities

whereby if higher quality relationships can be maintained, it should help to promote increased positive contact as the siblings become older, resulting in increased emotional well-being for both siblings.

The reasons behind the ASD and PWS sibling groups raised tendency towards adult anxiety requires further investigation. New research might focus on the lifelong behavioural difficulties of individuals with ASD or PWS; whereby the lower functioning individuals often have intensive, long-term specific care-needs to ensure their well-being (Cassidy \& Driscoll, 2009; Strunk, Pickler, McCain, Ameringer \& Myers, 2014), which can often result in feelings of social isolation for the carer (Strunk et al., 2014). This would be expected to have either a subliminal or overt affective influence upon the sibling, depending upon how involved they are in their sibling's day-to-day care needs. If the involvement is on a regular basis, it might take an exhaustive, emotional toll, leading to affective disorders symptomatology as it can do in mothers of autistic individuals (Baker, Seltzer \& Greenberg, 2011). If, however, the sibling plays a more distant role, it might be feelings of guilt that lead to affective symptomatology (Atkins, 1991).

Limitations to this study include the cross-sectional study design, which did not allow us to examine pre-existing developmental factors that might have an enduring influence on the individuals. Also we had no baseline marker and so we cannot know whether affective symptoms have increased or decreased since the siblings have reached adulthood. Further, we did not examine whether there was a subtle presence of characteristics of the broader autism phenotype, which might impact on sibling affective outcomes. Another limitation was the sample size of the sub-groups, due to the limited numbers, it did not allow for detailed analyses to be carried out on the individual groups. Finally, this study was carried out on a Caucasian, mainly middle-class, volunteer sample and consequently may not be generalizable to the wider population. 
Affective symptoms in adult siblings of people with developmental disabilities

However, a strength of our research was that we used a very closely matched control group, which ensured that we were measuring like-for-like and allowed for very tight control between the variables under investigation. We also had a relatively high number of participants, which should allow for individual variation in results and increased statistical power. The exception was for those with siblings with DUA but this is typical of this type of study (Hastings 2003).

In conclusion, our study has provided empirical evidence that adult siblings of individuals with disabilities do appear more vulnerable to the affective disorders than a closely matched group. We have also shown that the level of vulnerability is dependent upon the type of disability that the sibling has. The exception to this appears to be siblings of those with DS, who reported similar levels of affective symptomatology to the control group. The emotional wellbeing of siblings is a very important area of further study, due to more people with disabilities surviving into late adulthood, which means that the siblings may well have to assume responsibility for their welfare (Davys et al., 2015), this may well be alongside looking after children of their own and potentially caring for elderly parents. The affective state of the sibling therefore needs to be safeguarded if they are going to carry out these roles effectively. Previous suggestions have indicated that low levels of economic security are predictive of low levels of mental wellbeing in parents of children with disabilities (e.g., Falk et al., 2014); however, we could find no overall underlying demographic factor that could predict symptomatology in all of the adult sibling groups. Whilst this research has demonstrated the importance of eliminating factors that can cause symptomatology, we suggest that a focus on emotional cognitions and behaviours may prove a more productive area for future research into the causes of higher sibling levels of anxiety. While it is not expected that a single variable will explain the increased sibling tendency towards affective symptomatology, our study does highlight the importance of further research to try to 
Affective symptoms in adult siblings of people with developmental disabilities

ascertain which factors play a part in maintaining vulnerability; without an understanding of specific factors influencing vulnerability it is difficult to put effective intervention procedures into place.

Acknowledgements We would like to sincerely thank Professor Mike Boulton and Dr David Scott, who offered advice on aspects of the study.

Ethical standards The research associated with this article was subjected to the stringent standards set down by the University's Ethical Committee, which fully adheres to the ethical guidelines set out by the British Psychological Society.

Informed consent All participants gave their fully informed consent prior to participating in this research.

Conflict of interest There are no conflicts of interest.

\section{References}

Aguinis, H., \& Gottfredson, R.K. (2010). Best-practice recommendations for estimating interaction effects using moderated multiple regression. Journal of Organisational Behavior, 31, 776-786. DOI: 10.1002/job.686

Atkins, S.P. (1991). Siblings of learning disabled children: Are they special too? Child and Adolescent Social Work, 8, 525-533.

Baker, J.K., Seltzer, M.M., \& Greenberg, J.S. (2011). Longitudinal effects of adaptability on behavior problems and maternal depression in families of adolescents with autism. Journal of Family Psychology, 25, 601-609. doi: 10.1037/a0024409

Bank, S.P., \& Kahn, M.D. (1997). The sibling bond. New York: Harper Collins. 
Affective symptoms in adult siblings of people with developmental disabilities

Bjelland I., Dahl A.A., Haug T.T. \& Neckelmann D. (2002). The validity of the Hospital

Anxiety and Depression Scale: An updated literature review. Journal of

Psychosomatic Research, 52, 69-77.

Bjelland, I., Krokstad, S., Mykletun, A., Dahl, A.A., Tell, G.S., \& Tambs, K. (2008). Does a

higher educational level protect against anxiety and depression? The HUNT study.

Social Science and Medicine, 66, 1334-1345. doi: 10.1016/j.socscimed.2007.12.019.

Bramlett, M.D., \& Mosher, W.D. (2002). Cohabitation, marriage, divorce and remarriage in

United States. National Centre for Health Statistics. Vital Health Statistics, 23, 1-103. 103.

Brody, G.H. (2004). Siblings' direct and indirect contributions to child development. Current Directions in Psychological Science, 13, 124-126. doi: 10.1111/j.09637214.2004.00289.x

Cassidy, S.B., \& Driscoll, D.J. (2009). Prader-Willi syndrome. European Journal of Human Genetics, 17(1), 3-13. doi:10.1038/ejhg.2008.165

Cicirelli, V.G. (1995). Sibling relationships across the lifespan. New York: Plenum Press.

Copeland, W.E., Adair, C.E., Smetanin, P., Stiff, D., Briante, C., Colman, I. et al. (2013). Diagnostic transitions from childhood to adolescence to early adulthood. The Journal

of Child Psychology and Psychiatry, $\quad$ 54(7), 791-799. doi: 10.1111/jcpp.12062. 
Affective symptoms in adult siblings of people with developmental disabilities

Cuskelly, M., \& Gunn, P. (2006). Adjustment of children who have a sibling with Down syndrome: Perspectives of mothers, fathers and children. Journal of Intellectual Disability Research, 50, 917-925.

Davys, D., Mitchell, D., \& Haigh, C. (2015a). Futures planning: Adult life perspectives, British Journal of Learning Disabilities, 43, 219-226. DOI: 10.1111/bld.12099

Davys, D., Mitchell, D., \& Haigh, C. (2015b). Adult siblings consider the future: Emergent Themes. Journal of Applied Research in Intellectual Disabilities, (in press). doi.org/10.1111/jar.12172

Dimitropoulos, A., \& Schultz, R.T. (2007). Autistic-like symptomatology in Prader-Willi syndrome: A review of recent findings. Current Psychiatry Reports, 9, 159-164.

Falk, N.H., Norris, K., \& Quinn, M.G. (2014). The factors predicting stress, anxiety and depression in the parents of children with autism. Journal of Autism and Developmental Disorders, 44, 3185-3203. DOI10.1007/s10803-014-2189-4

Fletcher, J., Hair, N., \& Wolfe, B. (2012). Am I my brother's keeper? Sibling spillover effects: The case of developmental disabilities and externalising behaviour. NBER Working Paper No.18279. National Bureau of Economic Research, Cambridge, MA.

Frazier, P.A., Tix, A.P., \& Barron, K.E. (2004). Testing moderator and mediator effects in counselling psychology research. Journal of Counseling Psychology, 51, 115-134. DOI: $10.1037 / 0022-0167.5101 .115$ 
Affective symptoms in adult siblings of people with developmental disabilities

Gale C.R., Hatch S.L., Batty G.D. \& Deary I.J. (2009). Intelligence in childhood and risk of psychological distress in adulthood: The 1958 National Child Development Survey 1970 British Cohort Study. Intelligence, 37, 592-599. doi:10.1016/j.intell.2008.09

Giallo R. \& Gavidia-Payne S. (2006). Child, parent and family factors as predictors of adjustment for siblings with a disability. Journal of Intellectual Disability Research, 50, 937-948.

Gold, N. (1993). Depression and social adjustment in siblings of boys with autism. Journal of Autism and Developmental Disorders, 23, 147-163.

Gudmunson, C.G., Beutler, I.F., Israelsen, C.I., McCoy, J.K., \& Hill, E.J. (2007). Linking Financial Strain to Marital Instability: Examining the Roles of Emotional Distress and Marital Interaction. Journal of Family and Economic Issues, 28, 357-376. DOI $10.1007 / \mathrm{s} 10834-007-9074-7$

Hall C. (2006). A picture of the United Kingdom using the national statistics socio-economic classification. Retrieved from the Office for National Statistics website: $\underline{\text { http://www.statistics.gov.uk/article.asp?id=1663 }}$

Hannah, M.E., \& Midlarsky, E. (1999). Competence and adjustment of siblings of children with mental retardation. American Journal on Mental Retardation, 104, 2237.doi:10.1352/0895-8017(1999) 
Affective symptoms in adult siblings of people with developmental disabilities

Hartley, S.L., Barker, E.T., Baker, J.K., Seltzer, M.M., \& Greenberg, J.S. (2012). Marital satisfaction and life circumstances of grown children with autism across 7 years.

Journal of Family Psychology, 26(5), 688-697. doi:10.1037/a0029354.

Hastings R.P. (2003). Behavioural adjustment of siblings of children with autism engaged in applied behaviour analysis early intervention programs: The moderating role of social support. Journal of Autism and Developmental Disorders, 33, 141-150.doi:0162$3257 / 03 / 0200-0099 / 0$

Hastings R.P. (2007). Longitudinal relationships between sibling behavioural adjustment and behaviour problems of children with disabilities. Journal of Autism and Developmental Disorders, 37, 1485-1492.doi:10.1007/s10803-006-0230-y

Heller T. \& Kramer J. (2009). Involvement of adult siblings of persons with developmental disabilities future planning. Intellectual and Developmental Disabilities, 47, 208-219.doi/abs/10.1352/1934-9556-47.3.208

Hodapp R.M. \& Urbano R.C. (2007). Adult siblings of individuals with Down syndrome versus autism: $\quad$ Findings from a large-scale US survey. Journal of Intellectual Disability Research, 51, 1010-1029.doi:10.1111/j.1365-2788.2007.00994.x

Knight, S.J., Regan, R., Nicod, A., Horsley, S.W., Kearney,L., Homfrey, T...Flint, J. (1999). Subtle chromosomal rearrangements in children with unexplained mental retardation. Lancet, 354, 1676-1681. 
Affective symptoms in adult siblings of people with developmental disabilities

Krauss, M.W., Seltzer, M.M., Gordon, R., \& Friedman, D.H. (1999). Binding ties: The roles of adult siblings of persons with mental retardation. Mental Retardation, 34, 83-93.

Macks, J.R., \& Reeve, R.E. (2007). The adjustment of non-disabled siblings of children with autism. Journal of Autism and Developmental Disorders, 37, 10601067.doi:10.1007/s10803-006-0249-0

McHale S. \& Gamble W.C. (1989). Sibling relationships of children with disabled and nondisabled brothers and sisters. Developmental Psychology, 25, 421-429.

McLean, C.P., Asnaani, A., Litz, B.T., \& Hofmann, S.G. (2011). Gender differences in anxiety disorders: Prevalence, course of illness, comorbidity and burden of illness. Journal of Psychiatric Research, 45, 1027-1035.doi:10.1016/j.psychires.2011.03.006

Moore M.L., Howard V. \& McLaughlin T.F. (2002). Siblings of children with disabilities: A review and analysis. International Journal of Special Education, 17, 49- 63.

Orsmond, G.I., Kuo, H-Y., \& Seltzer, M.M. (2009). Siblings of individuals with an autistic spectrum disorder: Sibling relationships and wellbeing in adolescence and adulthood. Autism, 13(1), 59-80.doi:10.1177/1362361308097119.

Orsmond G.I. \& Seltzer M.M. (2007). Siblings of individuals with autism or Down syndrome: Effects on adult lives. Journal of Intellectual Disability Research, 51, 682696.doi:10.1111/j.1365-2788.2007.00954.x 
Affective symptoms in adult siblings of people with developmental disabilities

Petalas, M.A., Hastings, R.P., Nash, S., Lloyd, T., \& Dowey, A. (2009). Emotional and behavioural adjustment in siblings of children with intellectual disability with and without autism. Autism, 13, 471-483. doi:10.1177/1362361309335721.

Ross P. \& Cuskelly M. (2006). Adjustment, sibling problems and coping strategies of brothers and sisters of children with autistic spectrum disorder. Journal of Intellectual \& Developmental Disability, 31, 77-86.doi:10.1080/13668250600710864

Rossiter L. \& Sharpe D. (2001). The siblings of individuals with mental retardation: A quantitative review of the literature. Journal of Child and Family Studies, 10, 6584.doi:10.1023/A:1016629500708

Seltzer, M.M., Greenberg, J.S., Orsmond, G.I., \& Lounds, J. (2005). Life course studies of individuals with developmental disabilities. Mental Retardation, 43, 354-359.

Seltzer M.M., Orsmond G.I. \& Esbensen A.J. (2009). Siblings of individuals with autism spectrum disorder: Sibling relationships and wellbeing in adolescence and adulthood. Autism, 13, 59-80 doi: 10.1177/1362361308097119.

Smith, T., \& Perry, A. (2005). A sibling support group for brothers and sisters of children with autism. Journal of Developmental Disabilities, 11, 77-88.doi:10.1.1.473.566

Snaith R.P. (2003). The Hospital Anxiety and Depression Scale. Health and Quality of Life Outcomes, 1, 29.doi:10.1186/1477-7525-1-29

Stoneman, Z. (1989). Comparison groups in research on families with mentally retarded 
Affective symptoms in adult siblings of people with developmental disabilities

members: A methodological and conceptual review. American Journal of Mental Retardation, 95, 537-550.

Stoneman, Z., Brody, G.H., Davis, C.H., Crapps, J.M., \& Malone, D.M. (1991). Ascribed role relations between children with mental retardation and their younger siblings. American Journal on Mental Retardation, 95, 537-550.

Strunk, J.A., Pickler, R., McCain, N.L., Ameringer, S., \& Myers, B.J. (2014). Managing the health care needs of adolescents with autistic spectrum disorder: The parents' experience. Families, Systems and Health, 32, 3, 328-337.doi 10.1037/a0037180

Turnbull, A.P., \& Turnbull, H.R. III (1990). Families, professionals, and exceptionality: A special partnership (2 $2^{\text {nd }}$ ed.). New York: Macmillan.

Veltman, M.W.M., Thompson, R.J., Roberts, S.E., Thomas, N.S., Whittington, J., \& Boulton, P.F. (2004). Prader-Willi syndrome: A study comparing deletion and uniparental disomy cases with reference to autistic spectrum disorders. European Child \&Adolescent Psychiatry, 13, 42-50.

Voorpostel, M., \& Blieszner, R. (2008). Intergenerational solidarity and support between adult siblings. Journal of Marriage and Family, 70, 157-167.doi/10.1111/j.17413737.2007

Wolfe, B., Song, J., Greenberg, J.S., \& Mailick, M.R. (2014). Ripple effects of developmental disabilities and mental illness on nondisabled adult siblings. Social Science and Medicine, 108, 1-9.doi: 10.1016/j.socscimed.2014.01.021. 
Affective symptoms in adult siblings of people with developmental disabilities

Zigmond A.S. \& Snaith R.P. (1983). The Hospital Anxiety and Depression Scale. Acta

Psychiatrica Scandinavica, 67, 361-370. 
Affective symptoms in adult siblings of people with developmental disabilities

Table 1: Characteristics of the groups by sibling disability type shown as means (SDs) or frequencies (\%)

\begin{tabular}{|c|c|c|c|c|c|c|}
\hline Siblings & $\begin{array}{l}\mathrm{DS} \\
(N=59)\end{array}$ & $\begin{array}{l}\text { ASD } \\
(N=31)\end{array}$ & $\begin{array}{l}\text { PWS } \\
(N=26)\end{array}$ & $\begin{array}{l}\text { DUA } \\
(N=16)\end{array}$ & $\begin{array}{l}\text { Control } \\
(N=132)\end{array}$ & Test statistic \\
\hline Age (mean years) & $33.22(9.01)$ & $32.19(11.52)$ & $30.65(9.70)$ & $42.50(14.59)$ & $37.03(12.34)$ & $\begin{array}{l}F(4,254)=4.42 \\
p=0.002\end{array}$ \\
\hline Sex ( $\%$ female $)$ & $66.1 \%$ & $90.3 \%$ & $69.2 \%$ & $81.3 \%$ & $74.2 \%$ & $\begin{array}{l}F(4,259)=1.82 \\
p=0.13\end{array}$ \\
\hline Employment & $4.16(2.19)$ & $3.44(2.06)$ & $3.35(2.17)$ & $3.75(2.86)$ & $3.36(2.26)$ & $\begin{array}{l}F(4,237)=1.35 \\
p=0.25\end{array}$ \\
\hline Annual income & $3.68(2.05)$ & $2.87(1.85)$ & $2.77(2.14)$ & $3.13(1.77)$ & $3.11(1.96)$ & $\begin{array}{l}F(4,258)=1.45 \\
p=0.22\end{array}$ \\
\hline EducQualifications & $3.95(1.12)$ & $3.55(1.12)$ & $3.42(90.90)$ & $3.13(1.77)$ & $3.04(1.30)$ & $\begin{array}{l}F(4,254)=5.96 \\
p<0.001\end{array}$ \\
\hline MothEducQual & $2.98(1.36)$ & $2.39(1.45)$ & $2.46(0.88)$ & $1.00(1.12)$ & $1.96(1.47)$ & $\begin{array}{l}F(4,200)=7.42 \\
p<0.001\end{array}$ \\
\hline FathEducQual & $3.25(1.52)$ & $2.30(1.61)$ & $2.13(1.32)$ & $1.42(1.56)$ & $1.92(1.56)$ & $\begin{array}{l}F(4,195)=7.37 \\
p<0.001\end{array}$ \\
\hline \multicolumn{7}{|l|}{ Sib with Disabilities } \\
\hline Age & $32.57(6.36)$ & $29.66(12.48)$ & $28.92(11.02)$ & $40.98(13.20)$ & ----- & $\begin{array}{l}F(3,127)=5.76 \\
p=0.001\end{array}$ \\
\hline Severity Disability & $2.47(0.71)$ & $2.57(1.55)$ & $2.65(0.63)$ & $2.69(0.79)$ & ----- & $\begin{array}{l}F(3,125)=0.48 \\
p=0.70\end{array}$ \\
\hline Older than Sib \% & $55.9 \%$ & $58.1 \%$ & $53.8 \%$ & $31.3 \%$ & ----- & $\begin{array}{l}F(3,127)=1.22 \\
p=0.31\end{array}$ \\
\hline Primary Carer \% & $1.7 \%$ & $6.5 \%$ & $0.0 \%$ & $6.3 \%$ & ----- & $\begin{array}{l}F(3,127)=1.01 \\
p=0.39\end{array}$ \\
\hline
\end{tabular}

Table 2: Differences in anxiety and depression symptomatology between the groups 
Affective symptoms in adult siblings of people with developmental disabilities

\begin{tabular}{|c|c|c|c|c|c|c|}
\hline Siblings & $\begin{array}{l}\text { DS } \\
(N=59)\end{array}$ & $\begin{array}{l}\text { ASD } \\
(N=31)\end{array}$ & $\begin{array}{l}\text { PWS } \\
(N=26)\end{array}$ & $\begin{array}{l}\text { DUA } \\
(N=16)\end{array}$ & $\begin{array}{l}\text { Control } \\
(N=132)\end{array}$ & Test statistic \\
\hline Anxiety & $8.12(4.54)$ & $10.23(4.45)$ & $10.23(4.14)$ & $\begin{array}{c}9.50 \\
(2.97)\end{array}$ & $6.94(4.03)$ & $F(4,258)=6.24, p<0.001$ \\
\hline Depression & $3.85(2.80)$ & $4.81(2.94)$ & $4.73(3.34)$ & $\begin{array}{r}5.75 \\
(3.36)\end{array}$ & $3.19(3.06)$ & $F(4,259)=4.44, p=0.01$ \\
\hline
\end{tabular}


Affective symptoms in adult siblings of people with developmental disabilities

Table 3a: Correlations among study variables (siblings of individuals with DS below the diagonal / siblings of individuals with ASD above)

\begin{tabular}{|c|c|c|c|c|c|c|c|c|c|c|}
\hline & 1 & 2 & 3 & 4 & 5 & 6 & 7 & 8 & 9 & 10 \\
\hline 1.Anxiety & $\overline{---}$ & $69 * *$ & .35 & -.01 & .14 & .04 & .00 & -.02 & .06 & -.32 \\
\hline 2.Depression & $56^{* *}$ & --- & .21 & -.07 & .05 & -.04 & -.12 & -.12 & .10 & -.14 \\
\hline $\begin{array}{l}\text { 3.Gender } \\
\text { 4.Age }\end{array}$ & $\begin{array}{l}.27 * \\
-.09\end{array}$ & $\begin{array}{r}-.02 \\
.04\end{array}$ & $\begin{array}{l}--- \\
.06\end{array}$ & $\begin{array}{l}.09 \\
---\end{array}$ & $\begin{array}{r}-.22 \\
.34\end{array}$ & $\begin{array}{l}-.14 \\
.\end{array}$ & $\begin{array}{l}-.04 \\
-.11\end{array}$ & $\begin{array}{l}-.07 \\
-.03\end{array}$ & $\begin{array}{l}-.04 \\
-.05\end{array}$ & $\begin{array}{l}-.05 \\
-.27\end{array}$ \\
\hline $\begin{array}{l}\text { 5.Employmen } \\
\mathrm{t}\end{array}$ & .04 & .05 & -.25 & .01 & --- & $\begin{array}{l}44^{*} \\
5 \\
58^{*}\end{array}$ & .22 & -.01 & -.20 & .01 \\
\hline 6.AnnIncome & -.11 & .01 & $-.31 *$ & .01 & $79 * *$ & --- & .32 & .18 & .08 & .02 \\
\hline 7.EducLevel & .17 & .12 & -.01 & -.15 & $34 * *$ & .25 & --- & $48^{* *}$ & $50 * *$ & -.04 \\
\hline 8.MatEdLevel & $.28^{*}$ & .19 & -.04 & -.13 & $.30 *$ & $28 *$ & $.29 *$ & --- & $.41^{*}$ & -.31 \\
\hline 9.PatEdLevel & .17 & .18 & .01 & .01 & .16 & .09 & $41^{* *}$ & $45^{* *}$ & --- & .01 \\
\hline 10.Young/Old & $-.28 *$ & -.09 & .06 & $43 * *$ & .02 & .17 & -.07 & .07 & -.02 & --- \\
\hline
\end{tabular}

Key: ** Correlation is significant at the 0.01 level, $*$ Correlation is significant at the 0.05 level; EducLevel = educational qualifications; MatEdLevel = maternal educational qualifications;

PatEdLevel $=$ paternal educational qualifications; Young/old $=-$ participant whose is younger or older than their sibling with a disability.

Table 3b: Correlations among study variables (siblings of individuals with PWS below the diagonal / siblings of individuals with DUA above) 
Affective symptoms in adult siblings of people with developmental disabilities

\begin{tabular}{lcccccccccc}
\hline & $\mathbf{1}$ & $\mathbf{2}$ & $\mathbf{3}$ & $\mathbf{4}$ & $\mathbf{5}$ & $\mathbf{6}$ & $\mathbf{7}$ & $\mathbf{8}$ & $\mathbf{9}$ & $\mathbf{1 0}$ \\
\hline 1.Anxiety & --- & .42 & -.1 & .10 & -.28 & -.15 & -.19 & -.11 & -.17 & .16 \\
& & & 4 & & & & & & & \\
2.Depression & .18 & --- & -.0 & $.68^{* *}$ & -.27 & -.04 & -.54 & -.12 & .03 & -.20 \\
& & & 9 & & & & $*$ & & & \\
3.Gender & .08 & .10 & --- & .20 & .02 & .15 & .16 & .19 & -.32 & -.37 \\
4.Age & -.25 & -.06 & -.2 & --- & -.32 & .02 & -.39 & -.60 & -.55 & -.41 \\
& & & 1 & & & & & $*$ & & \\
5.Employmen & .18 & .09 & -.1 & .37 & --- &. & .41 & .24 & .57 & -.29 \\
t & & & 3 & & & $92^{* *}$ & & & & \\
6.AnnIncome & .09 & .16 & -.1 & $.43^{*}$ &. & --- & $.56^{*}$ & -.01 & .16 & -.49 \\
& & & 9 & & $70^{* *}$ & & & & & \\
7.EducLevel & .03 & .27 & -.0 & -.19 & .09 & -.01 & --- & .26 & .07 & .22 \\
& & & 6 & & & & & & & \\
8.MatEdLevel &. & -.36 & .07 & $-.54^{* *}$ & -.34 & -.37 & .03 & --- &. & $.61 * *$ \\
& $41 *$ & & & & & & & & $87 * *$ & \\
9.PatEdLevel & .05 & -.27 & .07 & -.04 & -.35 & -.31 & .20 & .07 & --- & .48 \\
10.Young/Old & .22 & $-.50^{* *}$ & .05 & .04 & .07 & -.07 & -.26 & .35 & -.05 & --- \\
\hline
\end{tabular}

Key: ** Correlation is significant at the 0.01 level, * Correlation is significant at the 0.05 level; EducLevel = educational qualifications; MatEdLevel = maternal educational qualifications;

PatEdLevel = paternal educational qualifications; Young/old $=$ - participant whose is younger or older than their sibling with a disability. 
Affective symptoms in adult siblings of people with developmental disabilities

Table 4: Moderating effects of gender, age, SES, participant and parental educational levels on the relationship between having a sibling with disabilities and standardised scores for anxiety

\begin{tabular}{llccccccc}
\hline Step and Variable & & $B$ & $S E B$ & $95 \%$ CI & $\beta$ & $($ sig) & $R^{2} \Delta$ & $($ sig $)$ \\
\hline Gender & & & & & & & & \\
Step 1 & SibWithDisbl & .45 & .11 & $.23, .67$ & .23 & $<.0001$ & & \\
& Gender & .45 & .14 & $-.19, .72$ & .19 & .001 & .09 & $<.0001$ \\
Step 2 & Gender x Sib & .19 & .27 & $-.34, .72$ & .09 & .49 & .00 & .49 \\
Age & & & & & & & & \\
Step 1 & SibWithDisbl & .47 & .12 & $.24, .70$ & .23 & $<.0001$ & & \\
& Age $(z$ score) & .03 & .06 & $-.08, .15$ & .03 & .57 & .05 & $<.0001$ \\
Step 2 & Age x Sib & -.20 & .12 & $-.42, .03$ & -.13 & .10 & .01 & .10 \\
SES & & & & & & & & \\
Step 1 & SibWithDisbl & .45 & .11 & $.23, .67$ & .23 & $<.0001$ & & \\
Step 2 & SES $(z$ Score) & -.08 & .06 & $-.20, .03$ & -.08 & .14 & .06 & $<.0001$ \\
Educ Level & SES x Sib & .02 & .11 & $-.20, .25$ & .02 & .85 & .00 & .85 \\
Step 1 & SibWithDisbl & .49 & .12 & $.26, .72$ & .42 & $<.0001$ & & \\
Step 2 & EdLevel $(z$ score) & -.04 & .06 & $-.16, .07$ & -.04 & .47 & .06 & $<.0001$ \\
MatEducLevel & EdLevel x Sib & .09 & .12 & $-.15, .32$ & .06 & .47 & .00 & .47 \\
Step 1 & SibWithDisbl & .43 & .12 & $.17, .69$ & .22 & .001 & & \\
Step 2 & Mat Educ $(z$ score $)$ & -.01 & .06 & $-.13, .12$ & -.01 & .93 & .05 & .004 \\
PatEducLevel & MatEd x Sib & .20 & .13 & $-.06, .45$ & .15 & .12 & .01 & .12 \\
Step 1 & SibWithDisbl & .53 & .13 & $.28, .79$ & .27 & $<.0001$ & & \\
Step 2 & Pat Educ $(z$ score) & -.06 & .07 & $-.19, .07$ & -.06 & .37 & .07 & $<.0001$ \\
\hline & PatEd x Sib & .10 & .13 & $-.16, .35$ & .07 & .46 & .01 & .46 \\
\hline
\end{tabular}

Table 5: Moderating effects of gender, age, SES, participant and parental educational levels on the relationship between having a sibling with disabilities and standardised scores for depression

\begin{tabular}{llccccccc}
\hline & $B$ & $S E B$ & $95 \%$ CI & $\beta$ & $($ sig) & $R^{2}$ & $($ sig) \\
& & & & & & & $\Delta$ & \\
\hline Gender & SibWithDisbl & .43 & .11 & $.21, .65$ & .21 & $<.0001$ & & \\
Step 1 & Gender & .38 & .14 & $.12, .65$ & .16 & .005 & .07 & $<.0001$ \\
& Gender x Sib & -.19 & .27 & $-.72, .34$ & -.09 & .48 & .00 & .48 \\
Step 2 & & & & & & & & \\
Age & SibWithDisbl & .49 & .11 & $.27, .71$ & .25 & $<.0001$ & & \\
Step 1 & Age $(z$ score) & .17 & .06 & $.06, .28$ & .17 & .003 & .08 & $<.0001$ \\
& Age x Sib & -.06 & .12 & $-.29, .17$ & -.04 & .60 & .00 & .60 \\
Step 2 & & & & & & & & \\
SES & SibWithDisbl & .43 & .11 & $.20, .65$ & .21 & $<.0001$ & & \\
Step 1 & SES $(z$ score) & -.08 & .06 & $-.19, .03$ & -.08 & .16 & .05 & $<.0001$ \\
Step 2 & SES x Sib & .13 & .11 & $-.10, .35$ & .09 & .26 & .00 & .26 \\
Educ Level & SibWithDisb1 & .49 & .12 & $.26, .71$ & .25 & $<.0001$ & & \\
Step 1 & EdLevel $(z$ score) & -.16 & .06 & -.27, & -.16 & .006 & .07 & $<.0001$ \\
& & & & -.05 & & & & \\
Step 2 & EdLevel x Sib & .17 & .12 & $-.06, .40$ & .11 & .14 & .00 & .14 \\
MatEducLeve & & & & & & & &
\end{tabular}


Affective symptoms in adult siblings of people with developmental disabilities

\begin{tabular}{llrrrrrrr}
$\boldsymbol{l}$ & & & & & & & & \\
Step 1 & SibWithDisbl & .39 & -.13 & $.14, .64$ & .20 & .003 & & \\
& MatEduc $(z$ & -.11 & .06 & $-.24, .01$ & -.12 & .08 & .05 & .005 \\
& Score) & & & & & & & \\
Step 2 & MatEd x Sib & .10 & .13 & $-.15, .34$ & .07 & .45 & .01 & .45 \\
PatEducLevel & & & & & & & & \\
Step 1 & SibWithDisbl & .45 & .12 & $.21, .79$ & .24 & $<.0001$ & & \\
& Pat Educ $(z$ score) & -.10 & .06 & $-.22, .07$ & -1.65 & .10 & .06 & .001 \\
Step 2 & PatEd x Sib & .15 & .12 & $-.09 . .40$ & .12 & .12 & .01 & .22 \\
\hline
\end{tabular}

SibWithDisbl = sibling with disabilities; $\mathrm{Sib}=$ sibling with disabilities; EducLevel = educational attainment level, MatEduc = maternal educational levels; PatEduc = paternal educational levels; $\mathrm{CI}$ = confidence interval; Sex Dummy Coding (males coded 0, females coded 1); Sibling with disabilities Dummy Coding (sibling without disabilities coded 0 , sibling with disabilities coded 1) 